\title{
Cartilage Protective and Chondrogenic Capacity of WIN-34B, a New Herbal Agent, in the Collagenase-Induced Osteoarthritis Rabbit Model and in Progenitor Cells from Subchondral Bone
}

\author{
Jeong-Eun Huh, ${ }^{1}$ Yeon-Cheol Park, ${ }^{2}$ Byung-Kwan Seo, ${ }^{2}$ Jae-Dong Lee, ${ }^{3}$ \\ Yong-Hyeon Baek, ${ }^{2}$ Do-Young Choi, ${ }^{3}$ and Dong-Suk Park ${ }^{2}$ \\ ${ }^{1}$ East-West Bone \& Joint Research Institute, Kyung Hee University, 149 Sangil-dong, Gangdong-gu, Seoul 134-727, Republic of Korea \\ ${ }^{2}$ Department of Acupuncture \& Moxibustion, Kang Dong Medical Center, Kyung Hee University, 149 Sangil-dong, Gangdong-gu, \\ Seoul 134-727, Republic of Korea \\ ${ }^{3}$ Department of Acupuncture \& Moxibustion, College of Korean Medicine, Kyung Hee University, 1 Hoegidong, Dongdawmungu, \\ Seoul 130-701, Republic of Korea \\ Correspondence should be addressed to Dong-Suk Park; icarus08@hanmail.net
}

Received 29 March 2013; Revised 5 June 2013; Accepted 3 July 2013

Academic Editor: Bo-Hyoung Jang

Copyright (C) 2013 Jeong-Eun Huh et al. This is an open access article distributed under the Creative Commons Attribution License, which permits unrestricted use, distribution, and reproduction in any medium, provided the original work is properly cited.

\begin{abstract}
We sought to determine the cartilage repair capacity of WIN-34B in the collagenase-induced osteoarthritis rabbit model and in progenitor cells from subchondral bone. The cartilage protective effect of WIN-34B was measured by clinical and histological scores, cartilage area, and proteoglycan and collagen contents in the collagenase-induced osteoarthritis rabbit model. The efficacy of chondrogenic differentiation of WIN-34B was assessed by expression of CD105, CD73, type II collagen, and aggrecan in vivo and was analyzed by the surface markers of progenitor cells, the mRNA levels of chondrogenic marker genes, and the level of proteoglycan, GAG, and type II collagen in vitro. Oral administration of WIN-34B significantly increased cartilage area, and this was associated with the recovery of proteoglycan and collagen content. Moreover, WIN-34B at $200 \mathrm{mg} / \mathrm{kg}$ significantly increased the expression of CD105, CD73, type II collagen, and aggrecan compared to the vehicle group. WIN-34B markedly enhanced the chondrogenic differentiation of CD105 and type II collagen in the progenitor cells from subchondral bone. Also, we confirmed that treatment with WIN-34B strongly increased the number of SH-2(CD105) cells and expression type II collagen in subchondral progenitor cells. Moreover, WIN-34B significantly increased proteoglycan, as measured by alcian blue staining; the mRNA level of type II $\alpha 1$ collagen, cartilage link protein, and aggrecan; and the inhibition of cartilage matrix molecules, such as GAG and type II collagen, in IL-1 $\beta$-treated progenitor cells. These findings suggest that WIN-34B could be a potential candidate for effective antiosteoarthritic therapy with cartilage repair as well as cartilage protection via enhancement of chondrogenic differentiation in the collagenase-induced osteoarthritis rabbit model and progenitor cells from subchondral bone.
\end{abstract}

\section{Introduction}

Osteoarthritis (OA) is a degenerative joint disease characterized by degradation and loss of articular cartilage, hypertrophic bone changes with osteophyte formation, and subchondral sclerosis $[1,2]$. The disease results from homeostatic imbalance between matrix synthesis and degradation of joint tissue [3].
Currently, the subchondral bone is recognized as a key factor in normal joint protection and chondrogenic differentiation. Subchondral bone has been shown to exert important shock absorbing and supportive function. Subchondral bone can decrease the joint load and supplies nutrients to cartilage. Moreover, researchers believe that factors produced locally by subchondral bone tissue seep through the bone-cartilage interface [4]. These changes then lead to reactivation of the 
secondary ossification centre and a decrease in cartilage thickness [5]. Cartilage defects that extend to the subchondral bone exhibit some ability to repair via the formation of neocartilage [6], probably due to the release of bone marrowderived stem cells from the underlying subchondral bone [7].

OA has traditionally been seen as a primary articular cartilage disorder. However, recent observations have demonstrated that both early-stage increased remodeling and bone loss, and late-stage slow remodeling and subchondral densification are important components of the OA pathogenesis [8]. In addition, subchondral bone is thought to play a key role in OA pathogenesis. Subchondral bone changes in OA are potentially both a result and a cause of cartilage loss. Subchondral bone stiffness may decrease its viscoelastic properties and produce a loss of shock absorbing capacity, which in turn causes significant mechanical load and breakdown of the overlying cartilage [9]. Cartilage damage may in turn negatively influence the subchondral bone, thus perpetuating a pathogenic circle in the OA joint. Consequently, modulation of subchondral bone remodeling may become an attractive approach for OA treatment.

Current strategies for OA treatment include decreasing joint pain and stiffness, improving joint function, and delaying surgery. Commonly prescribed OA medications include nonsteroidal anti-inflammatory drugs, analgesics, locally administered corticosteroids, and viscosupplementation, which provide only symptomatic relief and eventually result in the need for surgical intervention [10]. Until now, effective agents have not been found that significantly prevent progression of disease and aid recovery of tissue damage. The search continues for reliable therapeutic agents that influence subchondral bone remodeling and establish their potential role as disease-modifying OA drugs (DMOADs). These agents include antiresorptives (estrogens, selective estrogen receptor modulators, bisphosphonates, calcitonins, and osteoprotegerin and blocking RANKL antibodies), boneforming agents (parathormone and teriparatide), and antiosteoporotic agents with dual mechanism of action (strontium ranelate) [11]. However, there are still no DMOADs currently available to patients that can prevent disease progression and reverse the damage caused by OA [12].

To develop a novel antiosteoarthritis drug, we investigated the cartilage protection, analgesia, and anti-inflammation properties of 200 medicinal herbs used clinically for their anti-inflammatory and analgesic properties in traditional medicine. WIN-34B, a compound extracted from two herbs, the flowers of Lonicera japonica Thunb and roots of Anemarrhena asphodeloides BUNGE, was initially isolated through a comprehensive screening process. We standardized WIN-34B for quality control according to a previous report [13] and analyzed the major compounds of WIN-34B with the aim of standardizing its practical use and aiding in medicinal development. Data from several previous studies indicate that WIN-34B exhibits excellent analgesic and anti-inflammatory properties in the experimental models [13] and did not cause toxicity or gastric injury when orally administered to rats [14]. Also, WIN-34B showed that anti-inflammatory effect is mediate by reducing inflammatory mediators and regulating MMPs, ADAMTSs, and TIMPs via I $\kappa \mathrm{B}-\alpha$ and MAP kinases signal pathways in IL-1 $\beta$-stimulated human OA fibroblastlike synoviocytes [15]. Furthermore, WIN-34B has cartilage protective effects in osteoarthritis human cartilage explants culture and chondrocytes [16]. These results suggest that WIN-34B could be a potential candidate for effective antiosteoarthritic therapy with cartilage protective properties and without toxicity instead of existing OA treatment. However, little is known about the effects of WIN-34B on chondrogenic differentiation.

In this study, we investigated the effects of WIN-34B on cartilage protection and chondrogenic differentiation in the collagenase-induced osteoarthritis rabbit model and progenitor cells from subchondral bone.

\section{Materials and Methods}

2.1. Preparation of WIN-34B Extract and Standardization. The dried flowers of Lonicera japonica and the dried root of Anemarrhena asphodeloides from Song Lim Pharmaceutical Company (Seoul, Republic of Korea) were purchased and identified by the Korea Pharmaceutical Trading Association (Seoul, Republic of Korea). Voucher specimens of Lonicera japonica Thunb. (no. OA-LOJ-15) and Anemarrhena asphodeloides Bunge (no. OA-ANA-11) were analyzed by HPLC analysis and deposited in the Central Research Institute, WhanIn Pharm. Co. Ltd. (Suwon, Republic of Korea).

WIN-34B was prepared by extracting a mixture of $2 \mathrm{~kg}$ of dried Lonicera japonica flowers and $1 \mathrm{~kg}$ of Anemarrhena asphodeloides root $(2: 1, \mathrm{w} / \mathrm{w})$ with $10 \mathrm{~L}$ of $50 \%(\mathrm{v} / \mathrm{v})$ ethanol for $4 \mathrm{~h}$ at $85^{\circ} \mathrm{C}$. After the extracted solution was filtered and evaporated in vacuo, the resulting concentrate was dissolved in $225 \mathrm{~mL}$ distilled water and partitioned with $195 \mathrm{~mL} \mathrm{n}$ butanol. The $n$-butanol layer was evaporated in vacuo and lyophilized for complete removal of the residual solvent, resulting in a $7 \%$ yield of $11 \mathrm{~g}$ brown powder. We standardized WIN-34B for quality control according to a previous report [13], which we then analyzed by HPLC to find the standard compounds, mangiferin and chlorogenic acid.

\subsection{In Vivo Study}

2.2.1. Animals. Male New Zealand white rabbits $(2.8-3.0 \mathrm{~kg}$, nine to ten weeks) were obtained from the animal experimental center at Kyung Hee University Hospital (Seoul, Republic of Korea) and individually housed with water and food available ad libitum. The room was light/dark (08:00-20:00 h light, 20:00-08:00 h dark) controlled and kept at $21-24^{\circ} \mathrm{C}$. All experiments were conducted according to the "Guiding Principles for the Care and Use of Laboratory Animals" and all procedures approved by the Animal Care and Use Committee of Kyung Hee University Medical Center.

\subsubsection{Induction of Collagenase-Induced Osteoarthritis and} Drug Treatment. Rabbits aged nine to ten weeks and weighing $2.8-3.0 \mathrm{~kg}$ at the start of the experiment (day 1) were anesthetized with an intramuscular injection of $0.5 \mathrm{mg} / \mathrm{kg}$ tiletamine-zolazepam (Zoletil50, Virbac, France). The shaved right knee joints of all rabbits were intra-articularly injected 
with either $250 \mu \mathrm{L}$ of $4 \mathrm{mg} / \mathrm{mL}$ collagenase solution (Clostridium histolyticum type II, 425 units/mL enzyme activity) or saline (control group). The same collagenase injection procedure was applied once more on day 4 according to methods described in Mankin [17]. Following the initial injection of collagenase (day 1), the rabbits were divided into groups ( $n=10$ per group). For four weeks, the vehicle groups were orally treated with $20 \mathrm{~mL}$ distilled water and the experimental groups were orally treated with WIN-34B $(100,200$, and $400 \mathrm{mg} / \mathrm{kg}$ ), joins (ETCP, SK chemicals, $400 \mathrm{mg} / \mathrm{kg}$ ), celebrex (CEL, Pfizer, $100 \mathrm{mg} / \mathrm{kg}$ ), and glucosamine (Gluco-Hcl, Sigma, $1500 \mathrm{mg} / \mathrm{kg}$ ) on a daily basis using a feeding catheter (DJ2-284, Dae jong Ins. Korea).

2.2.3. Macroscopic Scoring of Stiffness. Stiffness was classified by movement, swelling, and reddening of knees. Each characteristic was subclassified as mild, moderate, and severe compared to the control group. The examination was performed by two independent observers who were blinded to the treatment groups.

2.2.4. Quantification of Global Histologic Score. After four weeks, the rabbits were sacrificed for histological examination. The right knee joints were then dissected and fixed in $10 \%$ phosphate-buffered formalin for two days, then decalcified in Calci-Clear Rapid solution (National Diagnostics, Atlanta, USA) for ten days, and then embedded in paraffin. Standard frontal sections of $5 \mu \mathrm{m}$ were stained with hematoxylin and eosin (H\&E) in the cartilage. Cartilage degradation features were analyzed using the scoring system developed by Colombo et al. [18] and modified by Kikuchi et al. [19]. The following six parameters were quantified: loss of superficial layer, erosion of cartilage, fibrillation and/or fissures, loss of stainable proteoglycan, disorganization of chondrocytes, and loss of chondrocytes. Each item was first graded from 1 to 4 (minimum to maximum damage) and the global histologic score was calculated as the total sum of each of the six parameters. All measurements were performed on the medial part of the tibial plateau, which is the region most affected by collagenase, and the femur condyle in the knee joint.

2.2.5. Quantification of Cartilage Area. All specimens were analyzed under bright-field microscopy (Axiovert 200, Carl Zeiss, Germany), and images were captured using a CCD camera (Axiocam MRc5, Carl Zeiss, Germany). The area of cartilage was measured in the whole of cartilage in the knee joints (100x magnification). All sections were evaluated by two independent observers blinded to the treatment groups. The results of these evaluations were then statistically analyzed.

2.2.6. Quantification of Proteoglycan by Safranin O Staining and Collagen by Masson's Trichrome Staining. These sections were also stained with Safranin O for detection of proteoglycan loss and Masson's trichrome for measurement of collagen in the cartilage. Cartilage depletion was indicated visually by diminished Safranin O staining and Masson's trichrome staining and was measured automatically with a Biocom microscope and AxioCam camera (Carl Zeiss, Germany). The proteoglycan content or collagen ratio of the cartilage was approximated by quantifying the staining intensity of the histologic sections [20, 21]. Intensity was measured in both the superficial and deep zone of the cartilage (100x magnification), and the ratio was calculated by dividing the Safranin O staining intensity (SOI) and the Masson's trichrome staining intensity (MTI) in the superficial zone by the SOI and MTI in the deep zone. All sections were evaluated by two independent observers blinded to the treatment groups. The results of these evaluations were then statistically analyzed.

2.2.7. Immunohistochemical Staining. Deparaffinized sections were pretreated with chondroitinase $A B C(1 \mathrm{U} / \mathrm{mL}$; SIGMA, St. Louis, MO, USA) at $37^{\circ} \mathrm{C}$ for $30 \mathrm{~min}$. The endogenous peroxidase was blocked with $3 \% \mathrm{H}_{2} \mathrm{O}_{2}$ in PBS at room temperature for $20 \mathrm{~min}$ and incubated in normal goat serum at room temperature for $30 \mathrm{~min}$. Immunodetection of type II collagen was performed by raising a new polyclonal rabbit antibody $(5 \mu \mathrm{g} / \mathrm{mL}$; MP Biomedicals Inc., CA, USA) against the six amino-acid sequence (EKGPDP) of the C telopeptide of type II collagen at $4^{\circ} \mathrm{C}$ overnight. Rabbit anti-aggrecan antibody (10 $\mu \mathrm{g} / \mathrm{mL}$; Affinity BioReagents, Golden, CO, USA) was used to evaluate the aggrecan at $4^{\circ} \mathrm{C}$ overnight. Rabbit anti-CD105 antibody and rabbit anti-CD73 antibody (Santa Cruz Biotechnology, CA, USA) were treated to detect mesenchymal stem cells. After reaction of the biotinylated rabbit antibodies against goat immunoglobulin G (IgG) (DAKO, Glostrup, Denmark) at room temperature for $30 \mathrm{~min}$, the sections were reacted with horseradish peroxidase-labeled streptavidin (DAKO) at room temperature for $15 \mathrm{~min}$. The color was developed with 3,3-diaminobenzidine tetrahydrochloride $(\mathrm{DAB})$ in $50 \mathrm{mmol} / \mathrm{L}$ of Tris- $\mathrm{HCl}, \mathrm{pH} 7.6,0.15 \mathrm{~mol} / \mathrm{L}$ of $\mathrm{NaCl}$, containing $0.05 \%$ Tween. Counterstaining was performed with hematoxylin. As a control, sections were reacted by replacing the first antibodies with nonimmune goat IgG (DAKO) at room temperature for $2 \mathrm{~h}$ before the immunostaining.

\subsection{In Vitro Study}

2.3.1. Isolation and Cultivation of Progenitor Cells from Rabbit Subchondral Bone. Subchondral bone was obtained from the knee joint of NewZealand white rabbit. To harvest progenitor cells from rabbit subchondral bone, bone was cut into small fragments, washed with phosphate buffered saline, and partially digested for $4 \mathrm{~h}$ at $37^{\circ} \mathrm{C}$ using $256 \mathrm{U} / \mathrm{mL}$ type I collagenase (Sigma-Aldrich, St Louis, MO, USA). The supernatant was discarded and the remaining fragments were placed in culture flasks and cultured in DMEM medium (Gibco-BRL, now part of Invitrogen Corporation, Carlsbad, CA, USA) containing $10 \%$ heat-inactivated FBS and an antibiotic mixture $(100$ units $/ \mathrm{mL}$ penicillin base and $100 \mu \mathrm{g} / \mathrm{mL}$ streptomycin) at $37^{\circ} \mathrm{C}$ in the humidified atmosphere. This medium was replaced every 2 days until cells were observed in the Petri dishes. At this point, the culture medium was replaced with 
fresh medium containing $10 \%$ FBS until confluence. Cells that reached $80 \%-90 \%$ confluence were passaged using trypsinEDTA in PBS $(0.05 \% \mathrm{v} / \mathrm{v}$, Gibco-BRL) and expanded into plates as passage 1 . Medium was exchanged every 3 days.

2.3.2. Flow Cytometry Analysis of Progenitor Cells and Chondrogenic Differentiation of Progenitor Cells from Rabbit Subchondral Bone. Mesenchymal progenitor cells from passage 2 of subchondral bone were washed in PBS/0.2\% BSA and stained with fluorescence-isothiocyanate- (FITC-) conjugated mouse anti-human CD73, CD90, and CD45 (BD Biosciences, San Diego, CA, USA) phycoerythrin- (PE-) conjugated anti-human CD105(SH-2), the activated leukocyte cell adhesion molecule (ALCAM, CD166), CD34, and CD11b (BD Biosciences, San Diego, CA, USA) for $15 \mathrm{~min}$ on ice. For indirect staining, cells were incubated $30 \mathrm{~min}$ with either mouse anti-human STRO-1 or rabbit anti-human type II collagen (Col II)-IgG, washed with PBS/0.2\% BSA, and stained with FITC-conjugated anti-mouse IgG (DAKO, Hamburg, Germany) for STOR-1 and PE-conjugated antirabbit IgG for Col II for $30 \mathrm{~min}$ at $4^{\circ} \mathrm{C}$.

Mesenchymal progenitor cells from passage 2 of subchondral bone were seeded in 6-well plates at a concentration of $5 \times 10^{5}$ cells $/ \mathrm{cm}^{2}$. After $24 \mathrm{~h}$, cells were treated or nontreated with WIN-34B $(10 \mu \mathrm{g} / \mathrm{mL})$ and cultured for 7 days and 14 days. Cells were stained with CD45 FITC/CD105 PE or CD45 FITC/Col II PE for $30 \mathrm{~min}$ at $4^{\circ} \mathrm{C}$. Cells were analyzed on FACScan (BD Biosciences, San Diego, CA, USA) using Cell Quest software (BD Biosciences San Diego, CA, USA).

2.3.3. Induction of Chondrogenic Differentiation in $I L-1 \beta$ Stimulated Progenitor Cells of Rabbit Subchondral Bone. Mesenchymal progenitor cells from passage 2 were trypsinized (passage 3 ), and $2 \times 10^{5}$ cells in $1 \mathrm{~mL}$ standard media were centrifuged at $1000 \mathrm{rpm}$ in $15 \mathrm{~mL}$ polypropylene. After overnight culture, media was changed to chondrogenic induction media. Chondrogenesis was induced by chondrogenic medium (high glucose DMEM medium supplemented with antibiotic mixture, $1 \% \mathrm{FBS}, 50 \mu \mathrm{g} / \mathrm{mL}$ ascorbic acid-2phosphate, $0.35 \mathrm{mM}$ proline, $1 \% \mathrm{ITS}^{+}, 10 \mathrm{ng} / \mathrm{mL}$ transforming growth factor- $\beta 3$ (TGF- $\beta 3$ ) [22]. Pellet of cells were treated with $5 \mathrm{ng} / \mathrm{mL}$ IL-1 $\beta$ (R\&D Systems, Minneapolis, USA) in the absence or presence for $1 \mathrm{~h}$ and then added WIN-34B (1, 10 and $20 \mu \mathrm{g} / \mathrm{mL}$ ). The medium was changed three times per week, and cells were maintained for up to 7 days.

(1) Histological Analysis of Alcian Blue Staining. Chondrogenic differentiation was histologically assessed by embedding micromasses in OCT compound and freezing, and cryosectioning at a thickness of $7 \mu \mathrm{m}$. Sections were stained with alcian blue, pH 1.0 (Rowley Biochemical, Danvers, MA, USA) to show proteoglycans.

(2) Colorimetric Analysis of GAG and Type II Collagen. GAG levels in the culture medium at seven days from onset of culture were determined by the amount of polyanionic material reacting with 1,9 -dimethylmethylene blue. Twenty microliter samples were mixed with $100 \mu \mathrm{L}$ of DMB reagents $(48 \mathrm{mg} / \mathrm{mL}$
DMB, $40 \mathrm{mM}$ glycine, $40 \mathrm{mM} \mathrm{NaCl}, 10 \mathrm{mM} \mathrm{HCl}, \mathrm{pH} 3.0$ ) for $30 \mathrm{~min}$ at room temperature and quantified by measuring the absorbance at $590 \mathrm{~nm}$ (Spectramax, Molecular Devices, Sunnyvale, CA, USA). All measurements were performed in quadruplicate. Quantification was performed using a standard curve of chondroitin 6-sulfate from shark cartilage (Sigma) in the range of $0-35 \mu \mathrm{g} / \mathrm{mL}$. Type II collagen levels were determined using the Sircol Collagen Assay (Biocolor Ltd., Valley Business Center, Northern Ireland). The culture medium at seven days from onset of culture was reacted with Sirius red dye containing sulfonic acid for $30 \mathrm{~min}$ at room temperature. The amount of type II collagen was calculated by measuring the absorbance at $540 \mathrm{~nm}$ and comparing that value to the standard concentration curve $(0-200 \mu \mathrm{g} / \mathrm{mL})$.

(3) Analysis of Real-Time Quantitative Reverse TranscriptionPolymerase Chain Reaction ( $q R T-P C R$ ). Total RNA was isolated using TRIzol reagent according to the manufacturer's protocol. Reverse transcription was performed by M-MLV Reverse Transcriptase (TaKaRa Biotechnology) according to the manufacturer's specifications. Briefly, first-strand cDNA was synthesized at $37^{\circ} \mathrm{C}$ for $1 \mathrm{~h}$ in $20 \mu \mathrm{L}$ reaction mixture using $1 \mu \mathrm{g}$ isolated mRNA. Real-time PCR (qRT-PCR) was carried out in a $25 \mu \mathrm{L}$ volume container with SYBR Green PCR Master Mix (Roche Diagnostics). The template source was either $5 \mathrm{ng}$ cDNA or purified DNA standard. The following primer sequences were used to amplify the type II $\alpha 1$ collagen, type I $\alpha 1$ collagen, cartilage link protein, and aggrecan (Table 1). $\beta$-actin was amplified as an internal control to standardize mRNA levels. Relative expression of the target genes in the study samples was obtained using the difference as calculated by the comparative threshold $\left(C_{t}\right)$ method. The cycle of threshold $\left(C_{T}\right)$ for each sample was averaged and normalized to GAPDH. The results were then analyzed by comparative $\Delta \Delta C_{T}$ method $\left(2^{\left(-\Delta \Delta C_{T}\right)}\right)$ for relative quantification of gene expression.

2.4. Statistical Analysis. Data were expressed as mean \pm SEM Differences among groups were analyzed by one-way ANOVA. In the case of two groups, a Student's $t$-test was used. Statistical significance was assessed at $P<0.05$.

\section{Results}

3.1. Effects of WIN-34B on Stiffness and Cartilage Loss in the Collagenase-Induced Osteoarthritis Rabbit Model. Administration of WIN-34B dose dependently reduced knee stiffness in one week after treatment compared to the vehicle. In contrast, there was no significant improvement of stiffness in the CEL, ETCP, and Gluco-Hcl (Figure 1(a)). After three weeks, CEL at $200 \mathrm{mg} / \mathrm{kg}$ and ETCP at $400 \mathrm{mg} / \mathrm{kg}$ reduced these symptoms when compared to the vehicle. WIN-34B exhibited some mild changes such as structure or chondrocyte loss (Figure 1(b)). Morever, WIN-34B at 100, 200, and $400 \mathrm{mg} / \mathrm{kg}$ led to $1.8-, 2.0-$, and 1.9-fold increases in cartilage area, respectively, compared to vehicle (Figure 1(c)). WIN$34 \mathrm{~B}$ at 200 and $400 \mathrm{mg} / \mathrm{kg}$ significantly decreased cartilage degradation of the tibial plateau (2.3- and 2.4-fold) and femur 
TABLE 1: Primers of targeted genes.

\begin{tabular}{|c|c|c|}
\hline mRNA & Primers & Annealing Tm (cycle) \\
\hline \multirow{2}{*}{ Type II $\alpha 1$ collagen } & Fw: $5^{\prime}$-AAC ACT GCC AAC GTC CAG AT- ${ }^{\prime}$ & \multirow{2}{*}{$58^{\circ} \mathrm{C}(32)$} \\
\hline & Rv: $5^{\prime}$-CTG CAG CAC GGT ATA GGT GA-3' & \\
\hline \multirow{2}{*}{ Type I $\alpha 1$ collagen } & Fw: $5^{\prime}$-TGA CCT CAA GAT GTG CCA CT- $3^{\prime}$ & \multirow{2}{*}{$58^{\circ} \mathrm{C}(32)$} \\
\hline & Rv: 5'-GGG AGT TTC CAT GAA GCC-3' & \\
\hline \multirow{2}{*}{ Cartilage link protein } & Fw: $5^{\prime}$-GCG TCC GCT ACC CCA TCT CTA-3' & \multirow{2}{*}{$55^{\circ} \mathrm{C}(32)$} \\
\hline & Rv: $5^{\prime}$-CTC TAA GGG CAC ATT CAC TT- $3^{\prime}$ & \\
\hline \multirow{2}{*}{ Aggrecan } & Fw: 5'-GAG GTC GTG GTG AAA GGT GT-3' & \multirow{2}{*}{$58^{\circ} \mathrm{C}(32)$} \\
\hline & Rv: $5^{\prime}$-GTG TGG ATG GGG TAC CTG AC-3' & \\
\hline \multirow{2}{*}{ GAPDH } & Fw: $5^{\prime}$-GCT CTC CAG AAC ATC ACT CCT GCC-3' & \multirow{2}{*}{$58^{\circ} \mathrm{C}(30)$} \\
\hline & Rv: $5^{\prime}$-CGT TGT CAT ACC AGG AAA TGA GCT T-3' & \\
\hline
\end{tabular}

Fw: forward; Rv: reverse; GAPDH: glyceraldehyde-3-phosphate dehydrogenase Tm: temperature.

condyle (1.8- and 2.2-fold), respectively, compared to the vehicle. Moreover, tibial plateau and femur condyle change tended to be higher in the WIN-34B at 200 and $400 \mathrm{mg} / \mathrm{kg}$ compared to other experimental groups (CEL, ETCP, and Gluco-Hcl) (Figure 1(d)).

3.2. Effects of WIN-34B on Cartilage Protection in the Collagenase-Induced Osteoarthritis Rabbit Model. Cartilage protective effects of WIN-34B were also evaluated by Safranin O staining for detection of proteoglycan loss and Masson's trichrome staining for measurement of collagen in the cartilage. In the normal, proteoglycan and collagen contents preserved in the knee joints, but not resulting in a marked loss of proteoglycan and collagen in the collagenase-induced knee joints (Figures 2(a) and 2(c)). WIN-34B at 100, 200, and $400 \mathrm{mg} / \mathrm{kg}$ increased the ratio of SOI (1.8-, 2.1-, and 2.0- fold) and MTI (2.2-, 4.2-, and 3.7-fold), respectively, compared to the vehicle. This ratio was also significantly higher in the WIN-34B at 100, 200, and $400 \mathrm{mg} / \mathrm{kg}$ compared to other experimental groups (CEL, ETCP, and Glugo-Hcl) (Figures 2(b) and 2(d)).

3.3. Effects of WIN-34B on Chondrogenic Differentiation in the Collagenase-Induced Osteoarthritis Rabbit Model. According to immunohistochemical analysis, WIN-34B at $200 \mathrm{mg} / \mathrm{kg}$ enhanced the expression of positive cells for CD105 (16.6fold), CD73 (9.0-fold), type II collagen (13.1-fold), and aggrecan (7.9-fold) compared to cartilage area of vehicle (Figures 3(a) and 3(b)). Also, treatment with WIN-34B at $200 \mathrm{mg} / \mathrm{kg}$ enhanced the expression of CD105 (2.6-fold) and CD73 (2.7fold) in the subchondral bone zone (Figures 3(c) and 3(d)).

\subsection{Effects of WIN-34B on Chondrogenic Differentiation of} Progenitor Cells from Rabbit Subchondral Bone. Expended progenitor cells showed typical cell surface antigens of mesenchymal stem and progenitor cells (Figure 4(a)). The antigens CD73, SH-2, CD90, and CD166 were present in progenitor cells from rabbit subchondral bone. Cells were positive for CD73 (44\%), SH-2 (2-6\%), CD90 (39\%), CD166 (27\%), and STRO-1 (31\%). A population of cells were minority positive for $\mathrm{SH}-2$, and negative for the hematopoietic antigen CD34 as well as for the leukocyte common antigen CD45 and macrophage antigen CD11b (Figure 4(a)). We also investigated the in vitro effects of WIN-34B on chondrogenic differentiation of progenitor cells derived from rabbit subchondral bone using flow cytometry analysis. The surface antigen for SH-2 was increased by $39 \%$ at 7 days and $52 \%$ at 14 days of culture in chondrogenic medium, and the expression of type II collagen was enhanced by $8-11 \%$ at 7 days and 14 days (Figure 5(b)). WIN-34B at $10 \mu \mathrm{g} / \mathrm{mL}$ increased the number of SH-2 cells ( $96 \%$ and $98 \%$ ) and expression of type II collagen (23\% and $19 \%)$ at 7 days and 14 days after cultivation, respectively (Figure $4(\mathrm{~b})$ ).

3.5. Effects of WIN-34B on Chondrogenic Differentiation of IL$1 \beta$-Treated Progenitor Cells from Rabbit Subchondral Bone. To evaluate the effects of WIN-34B on the chondrogenic differentiation of IL-1 $\beta$-treated progenitor cells, cells were cultured in high-density pellets of chondrogenic conditions and added WIN-34B at 1,10 , and $20 \mu \mathrm{g} / \mathrm{mL}$. According to histological analysis, IL-1 $\beta$-treatment of subchondral progenitor cells led to an 8.0 -fold reduction in proteoglycan expression compared to the control. However, treatment with WIN-34B at 1, 10, and $20 \mu \mathrm{g} / \mathrm{mL}$ led to 3.2-, 6.0-, and 9.7-fold increases, respectively, compared to the IL- $1 \beta$-treated subchondral progenitor cells (Figure 5(a)). The level of chondrogenic markers was determined by qRT-PCR. IL- $1 \beta$ significantly decreased the mRNA expression of type II $\alpha 1$ collagen, cartilage link protein, and aggrecan. However, WIN-34B dose dependently increased the level of type II $\alpha 1$ collagen, cartilage link, and aggrecan compared to IL- $1 \beta$-treated cells (Figure 5(b)). Moreover, WIN-34B dose dependently reduced the degradation of GAG and type II collagen induced by IL- $1 \beta$ compared to IL- $1 \beta$ treated cells (Figure 5(c)).

\section{Discussion}

In this study, we investigated the effects of WIN-34B on cartilage protection and chondrogenic differentiation in the progress of OA. First, in the collagenase-induced osteoarthritis rabbit model, we evaluated the stiffness and cartilage loss to assess the effects of WIN-34B on disease progression. Cartilage protective effect was confirmed by determining 


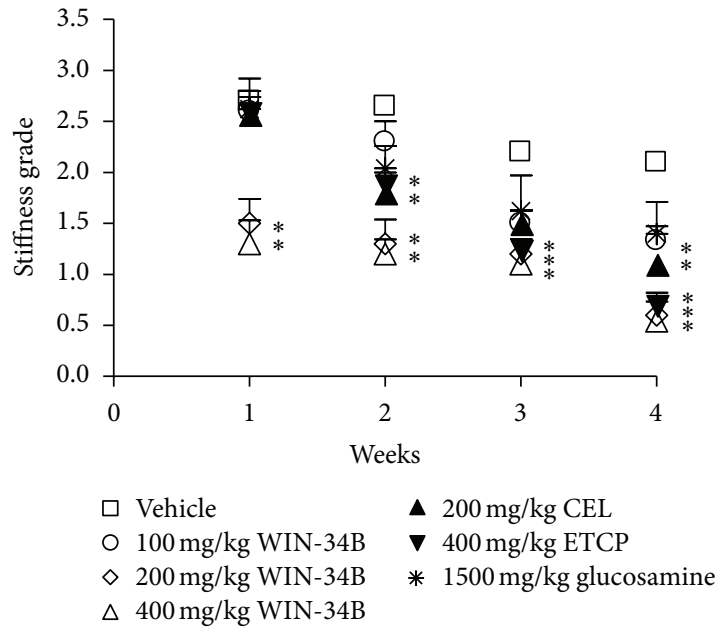

(a)

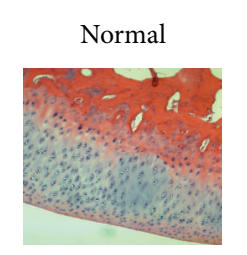

WIN-34B $400 \mathrm{mg} / \mathrm{kg}$



Vehicle

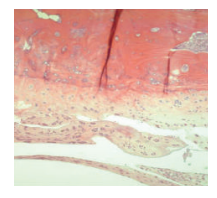

CEL $200 \mathrm{mg} / \mathrm{kg}$

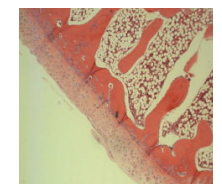

WIN-34B 100 mg/kg WIN-34B 200 mg/kg

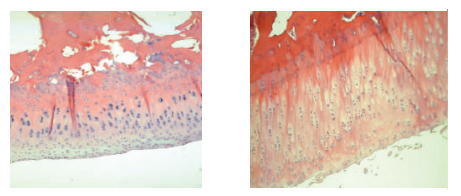

ETCP $400 \mathrm{mg} / \mathrm{kg}$ Gluco-Hcl $1500 \mathrm{mg} / \mathrm{kg}$
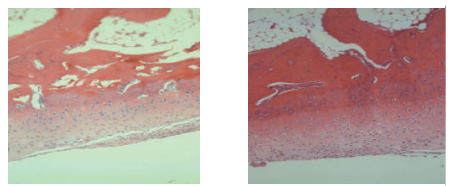

(b)

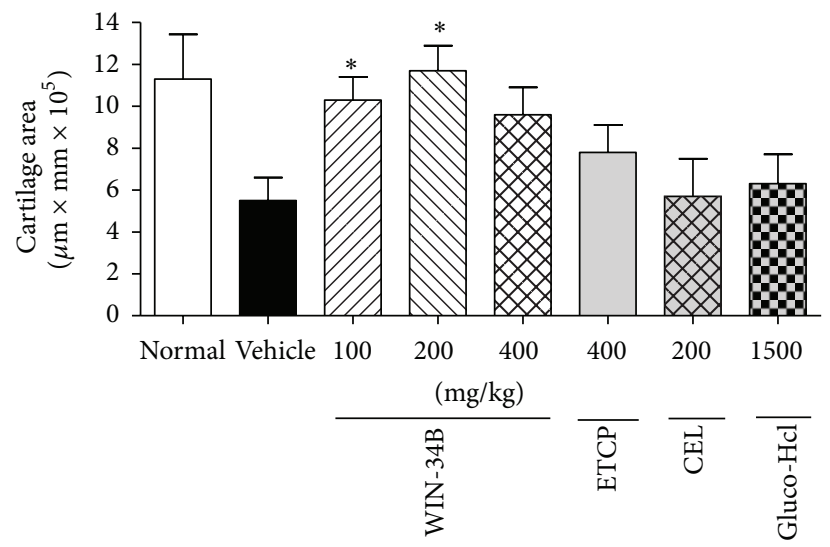

(c)

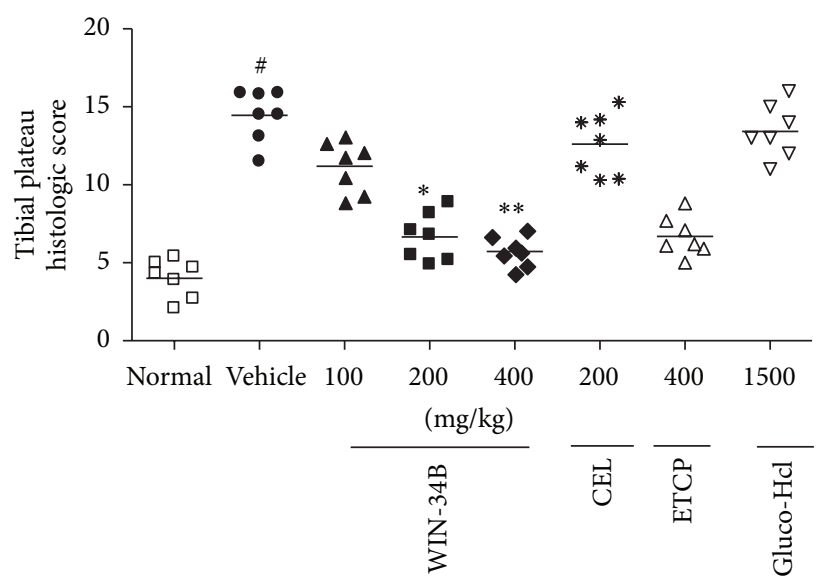

(d)

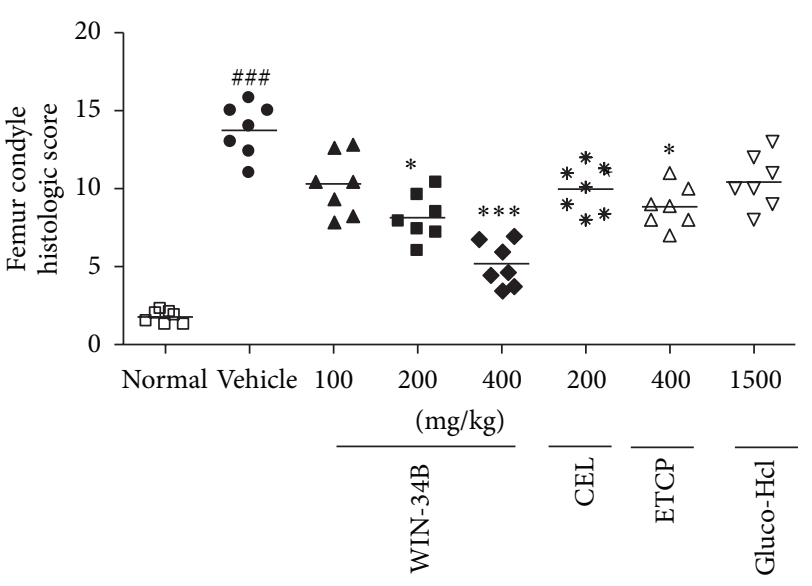

FIGURE 1: Effects of WIN-34B on disease progression in the collagenase-induced arthritis rabbit model. Right knees of rabbits were intraarticularly injected with collagenase on days 1 and $4.100 \mathrm{mg} / \mathrm{kg}, 200 \mathrm{mg} / \mathrm{kg}$, and $400 \mathrm{mg} / \mathrm{kg}$ WIN-34B; $200 \mathrm{mg} / \mathrm{kg} \mathrm{CEL;} 400 \mathrm{mg} / \mathrm{kg} \mathrm{ETCP}$ or $1500 \mathrm{mg} / \mathrm{kg}$ Gluco-Hcl were orally administered for four weeks. (a) Stiffness (b) Hematoxylin-Eosin stained sections of knee joints from the normal, vehicle, WIN-34B $100 \mathrm{mg} / \mathrm{kg}$, WIN-34B $200 \mathrm{mg} / \mathrm{kg}$, WIN-34B $400 \mathrm{mg} / \mathrm{kg}$, CEL $200 \mathrm{mg} / \mathrm{kg}$, ETCP $400 \mathrm{mg} / \mathrm{kg}$, and Gluco-Hcl $1500 \mathrm{mg} / \mathrm{kg}$. (c) Cartilage area and (d) histopathologic scores evaluated at the tibial plateau and femur condyle in animals with collagenaseinduced arthritis. Values are the mean \pm SEM. ${ }^{\#} P<0.05$ and ${ }^{\# \# \#} P<0.001$ compared to the normal group, ${ }^{*} P<0.05$, ${ }^{* *} P<0.01$, and ${ }^{* * *} P<0.001$ compared to the vehicle group. Two independent experiments were performed with similar results. 


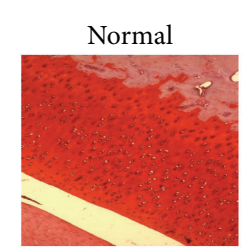

WIN-34B $400 \mathrm{mg} / \mathrm{kg}$
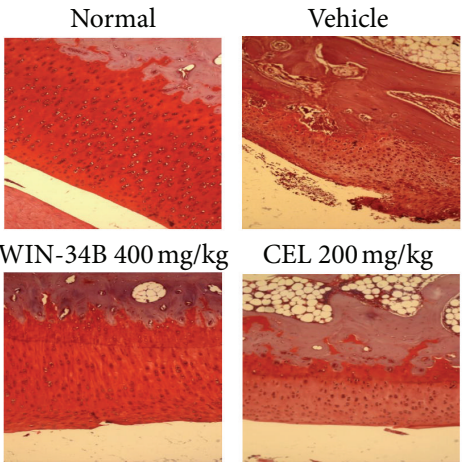

CEL $200 \mathrm{mg} / \mathrm{kg}$

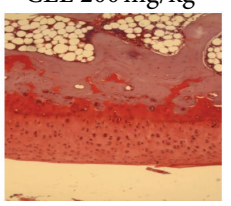

(a)

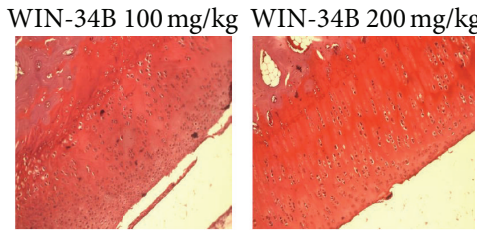

ETCP $400 \mathrm{mg} / \mathrm{kg}$ Gluco-Hcl $1500 \mathrm{mg} / \mathrm{kg}$
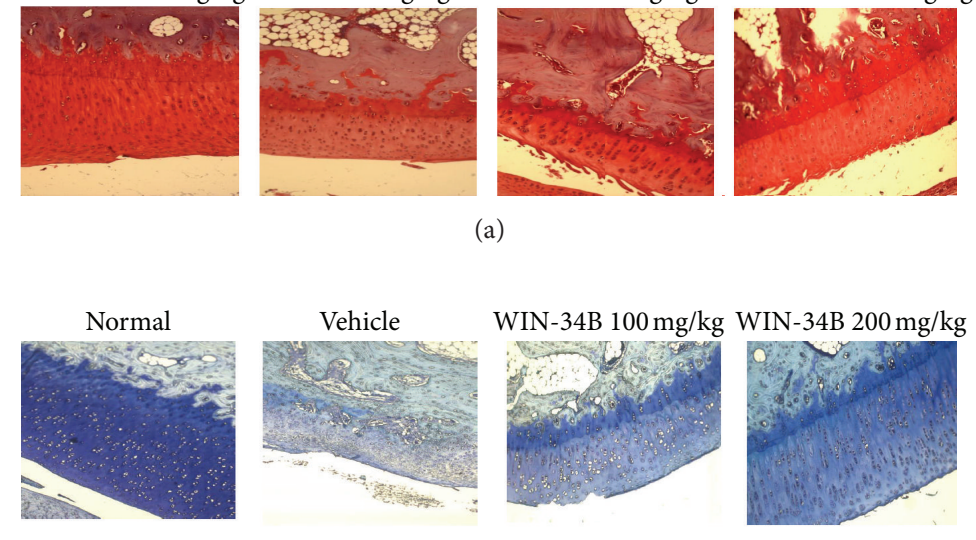

WIN-34B $400 \mathrm{mg} / \mathrm{kg}$
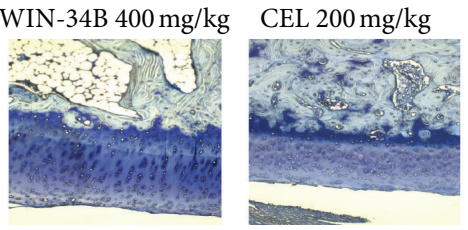

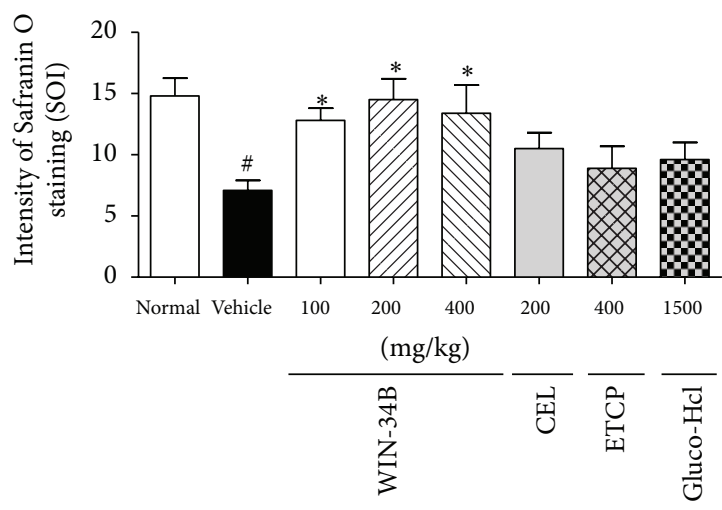

(b)

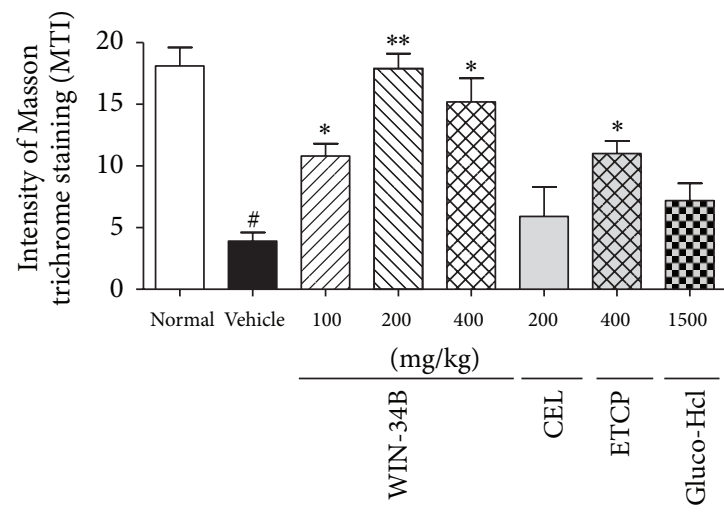

(d)

FIGURE 2: Effects of WIN-34B on cartilage protection in the knees of collagenase-induced arthritis rabbits. (a) Representative Safranin O stained sections of knee joints from the normal, vehicle, WIN-34B $100 \mathrm{mg} / \mathrm{kg}$, WIN-34B $200 \mathrm{mg} / \mathrm{kg}$, WIN-34B $400 \mathrm{mg} / \mathrm{kg}, \mathrm{CEL} 200 \mathrm{mg} / \mathrm{kg}$, ETCP $400 \mathrm{mg} / \mathrm{kg}$, and Gluco-Hcl $1500 \mathrm{mg} / \mathrm{kg}$ group. (b) Proteoglycan content, expressed as a ratio, was calculated by dividing the Safranin O staining intensity (SOI) in the superficial zone (SOI-S) by SOI in the deep zone (SOI-D). (c) Representative Masson's trichrome stained sections of knee joints from the normal, vehicle, WIN-34B $100 \mathrm{mg} / \mathrm{kg}$, WIN-34B $200 \mathrm{mg} / \mathrm{kg}$, WIN-34B 400 mg/kg, CEL 200 mg/kg, ETCP $400 \mathrm{mg} / \mathrm{kg}$ and Gluco-Hcl $1500 \mathrm{mg} / \mathrm{kg}$ group. (d) Collagen content, expressed as a ratio, was calculated by dividing the Masson's trichrome staining intensity (MTI) in the superficial zone (MTI-S) by MTI in the deep zone (MTI-D). Values are mean \pm SEM. ${ }^{\#} P<0.05$ compared to the normal group, ${ }^{*} P<0.05$ and ${ }^{* *} P<0.01$ compared to the vehicle group. Two independent experiments were performed with similar results.

proteoglycan and collagen contents. Chondrogenic capacity of WIN-34B was assessed by the expression of CD105, CD73, type II collagen, and aggrecan using the immunohistochemical analysis. Second, we evaluated the expression of mesenchymal stem cell-related cell surface antigen to assess the chondrogenic induction of progenitor cells from subchondral bone by WIN-34B treatment in chondrogenic medium. The cartilage protective and chondrogenic capacity of WIN-34B was assessed by alcian blue staining of proteoglycan, the mRNA levels of chondrogenic maker genes, and the degradation of GAG and type II collagen in IL- $1 \beta$-treated progenitor cells from rabbit subchondral bone.

Oral administration of WIN-34B resulted in a significant reduction of general clinical and histological scores. Also, WIN-34B significantly inhibited cartilage loss, as determined by measuring the proteoglycan and collagen. However, histopathology grading showed that CEL and Gluco-Hcl had no protective effect on cartilage, and ETCP resulted in significantly degraded cartilage in the femur condyle, but not the tibial plateau. These results suggest that WIN-34B is markedly more effective against cartilage destruction than the selective COX-2 inhibitor, ETCP, and Gluco-Hcl in the collagenaseinduced osteoarthritis rabbit model. Our previous in vitro data on WIN-34B has shown cartilage protective effects through the regulation of matrix proteinases (aggrecanases and MMPs/TIMPs), inflammatory mediators (PGE2, NO, IL$1 \beta$, and TNF- $\alpha$ ), and the MAPK pathways in osteoarthritis human cartilage explants culture and chondrocytes [15]. These results support the safety and therapeutic usefulness of WIN-34B for development as an OA treatment.

The ultimate goal of OA treatment is cartilage protection and repair but is not yet clear. Although, various surgical methods have been proposed to regenerate articular cartilage, including bone marrow stimulation [23], mosaicplasty [24], and autologous chondrocyte implantation [25], each of them has some disadvantage such as degeneration of repaired tissue, limitation of large defects, and long-term risk of developing OA [26].

There have been many reports of new DMOAD candidates with strong cartilage protective and chondrogenic 

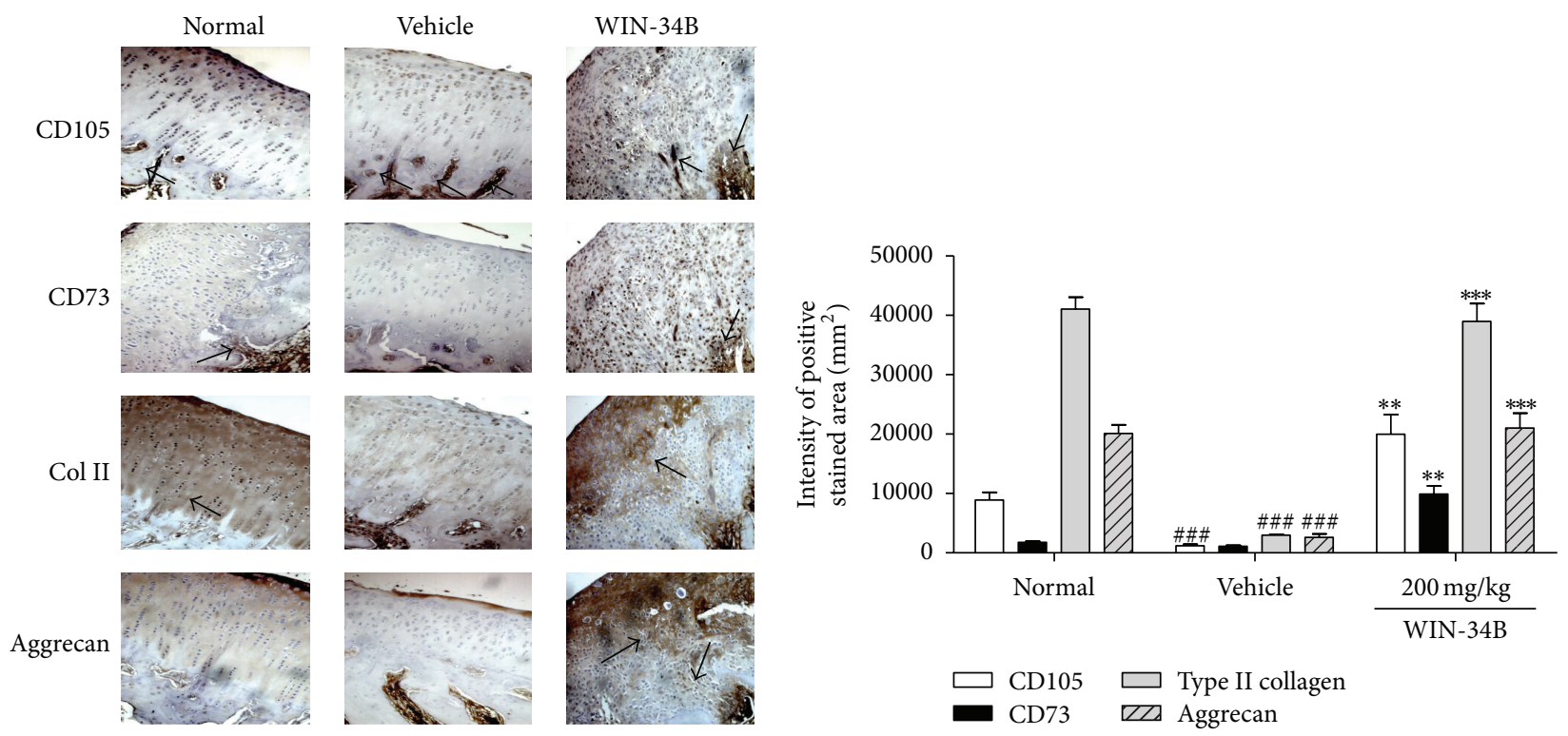

(a)

(b)
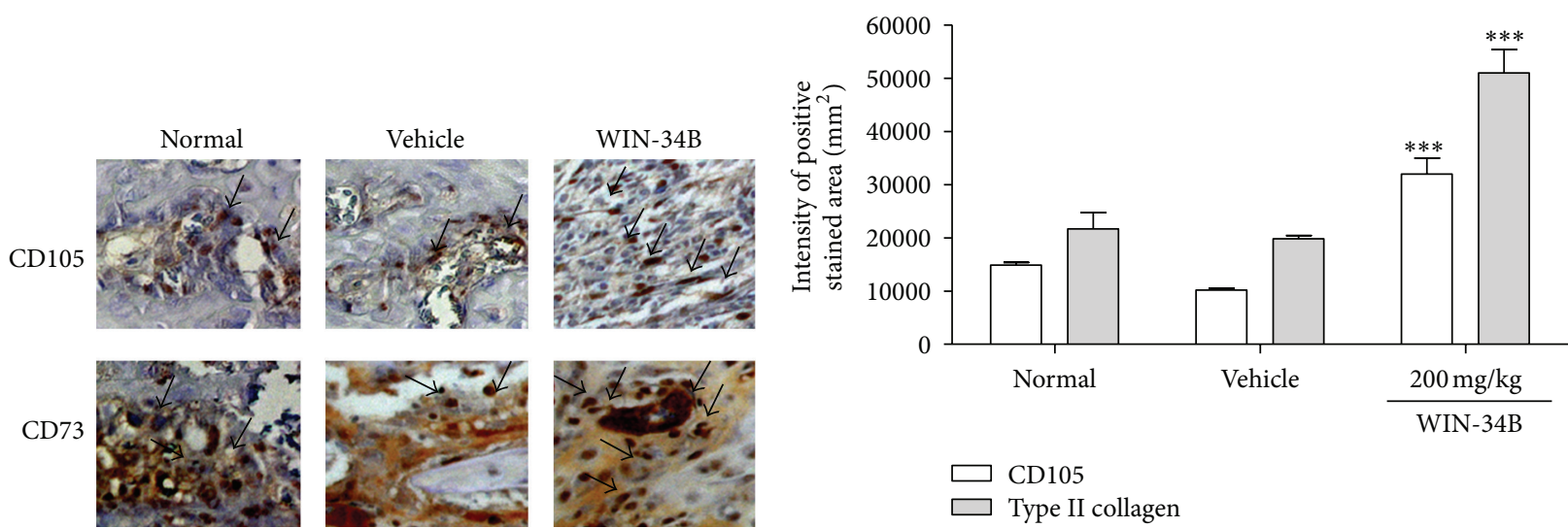

(c)

(d)

FIGURE 3: Effects of WIN-34B on chondrogenic differentiation in the knees of collagenase-induced arthritis rabbits. (a) Representative immunostained stained sections of cartilage from knee joints of animal in the normal, vehicle, and WIN-34B $200 \mathrm{mg} / \mathrm{kg}$ group. Lane 1: rabbit anti-CD105 antibody stained sections, lane 2: rabbit anti-CD73 antibody stained sections, lane 3: rabbit-anti-type II collagen (Col II) antibody stained sections, lane 4: rabbit-anti-aggrecan antibody stained sections. (b) Intensity of positive stained area of anti-CD105, antiCD73, anti-type II collagen, and anti-aggrecan by immunostaining in the cartilage zone of knee joints. (c) Representative immunostained stained sections of subchondral bone from the knee joints of animals in the normal, vehicle, and WIN-34B 200 mg/kg groups. Lane 1: rabbit anti-CD105 antibody stained sections, lane 2: rabbit anti-CD73 antibody stained sections. (d) Intensity of positive stained area of anti-CD105 and anti-CD73 in the subchondral bone zone of knee joints. Values are the mean \pm SEM. ${ }^{\# \#} P<0.01$ compared to the normal group, ${ }^{* *} P<0.05$ and ${ }^{* * *} P<0.01$ compared to the vehicle group. Two independent experiments were performed with similar results.

activities. Antiresorptive agents, such as estrogens, and other bisphosphonates (BP) have been shown to have a chondroprotective function and a favorable effect in stopping OA progression in animal models [27-33]. Recently, selective estrogen receptor modulators (SERMs) have also demonstrated similar positive effects in OA treatment [27]. However, results from clinical trials using these drugs have been contradictory [34]. Bone-forming agents such as PTH (134) inhibited the terminal differentiation of human articular chondrocytes in vitro and reduced the progression of cartilage damage in a model of papain-induced OA in rats [35]. Strontium ranelate is an agent with dual mechanisms of action on bone metabolism, exerting antiresorptive and new bone forming effects [36]. However, there are few studies on the use of PTH (1-34) and strontium ranelate in animal models of OA, so more research need to be carried out. Therefore, it is reasonable to assume that drugs affecting subchondral bone remodeling may have a prominent role as DMOADs. While various attempts have been made to develop DMORDs, the results have been unsatisfactory regarding the effects and safety of these drugs [37].

Progenitor cells of subchondral bone were expected to be an alternative for cartilage repair of OA. Many researchers agree with the importance of subchondral bone healing in 

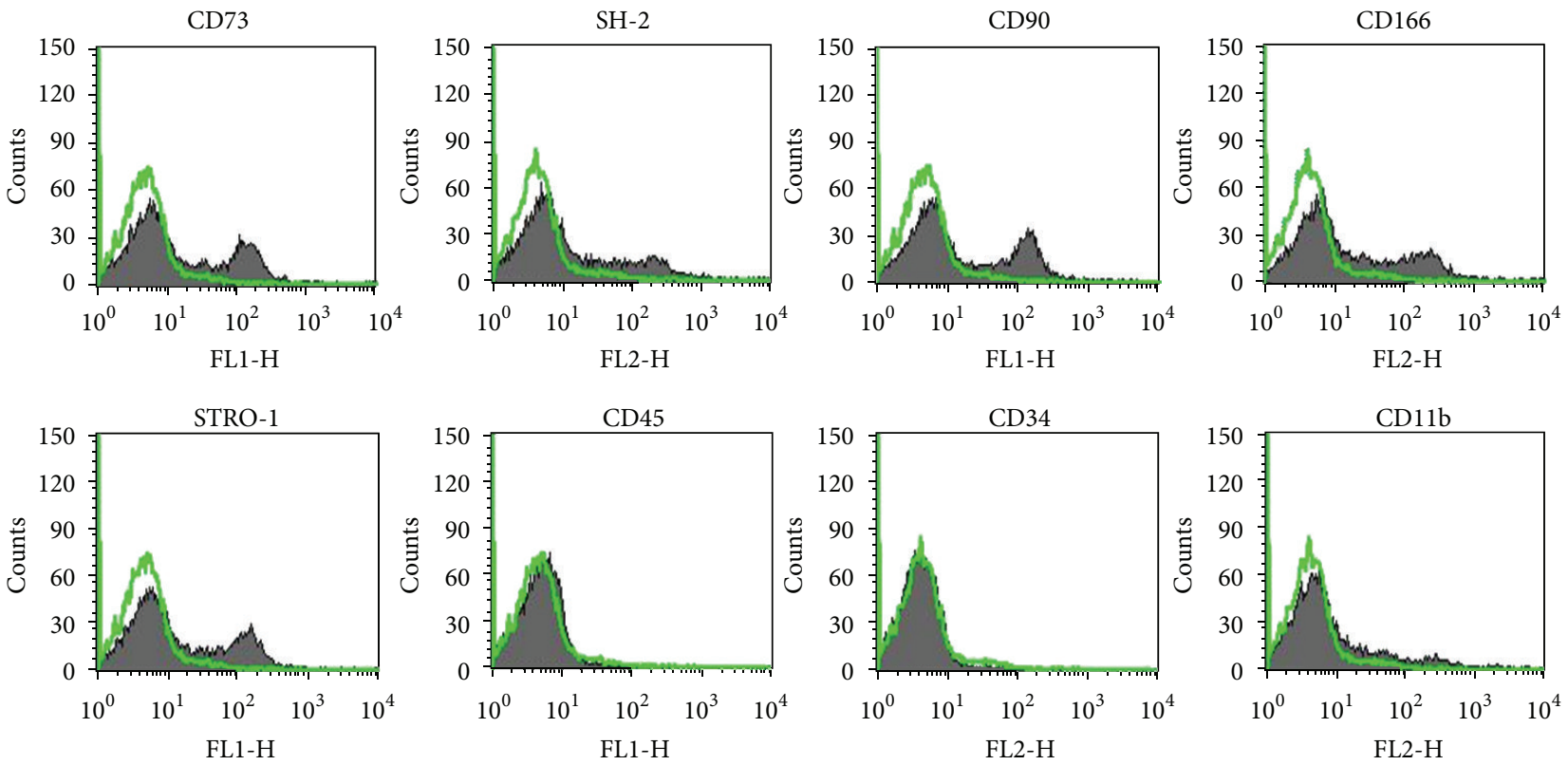

(a)
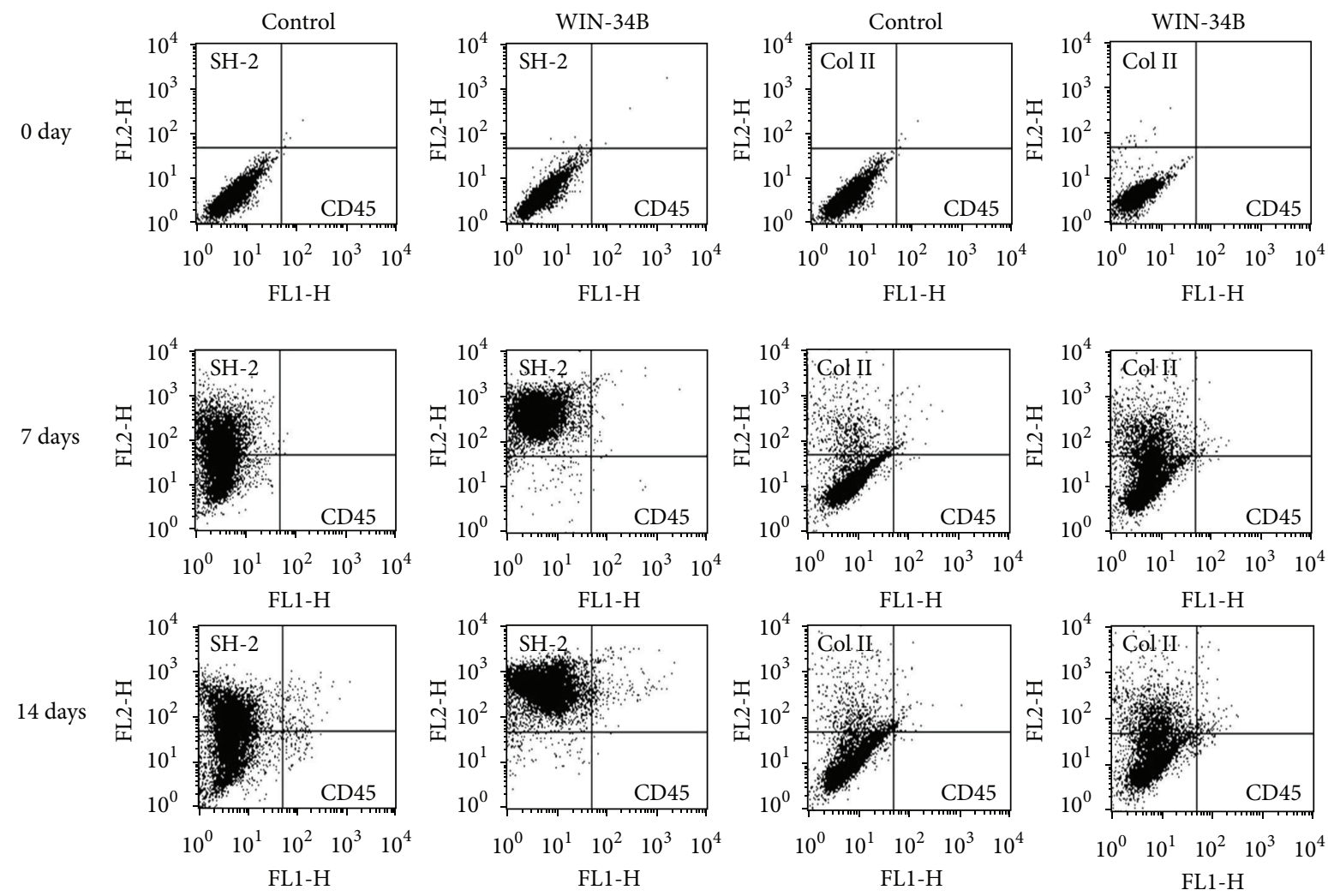

(b)

FIGURE 4: Effects of WIN-34B on chondrogenic differentiation of progenitor cells from rabbit subchondral bone. (a) Surface marker profiling of progenitor cells using flow cytometry. Cells were positive for CD73, SH-2, CD90, CD166, and STOR-1, and negative for CD45, CD34, and CD11b. (b) Chondrogenic induction of progenitor cells from subchondral bone cultured by WIN-34B treatment in chondrogenic medium. Progenitor cells from passage 2 of subchondral bone were seeded in 6 -well plates at a concentration of $5 \times 10^{5} \mathrm{cells} / \mathrm{cm}^{2}$. After $24 \mathrm{~h}$, cells were treated or nontreated with WIN-34B $(10 \mu \mathrm{g} / \mathrm{mL})$ and cultured for 7 days and 14 days. Each of the three samples was measured for profiling markers. 


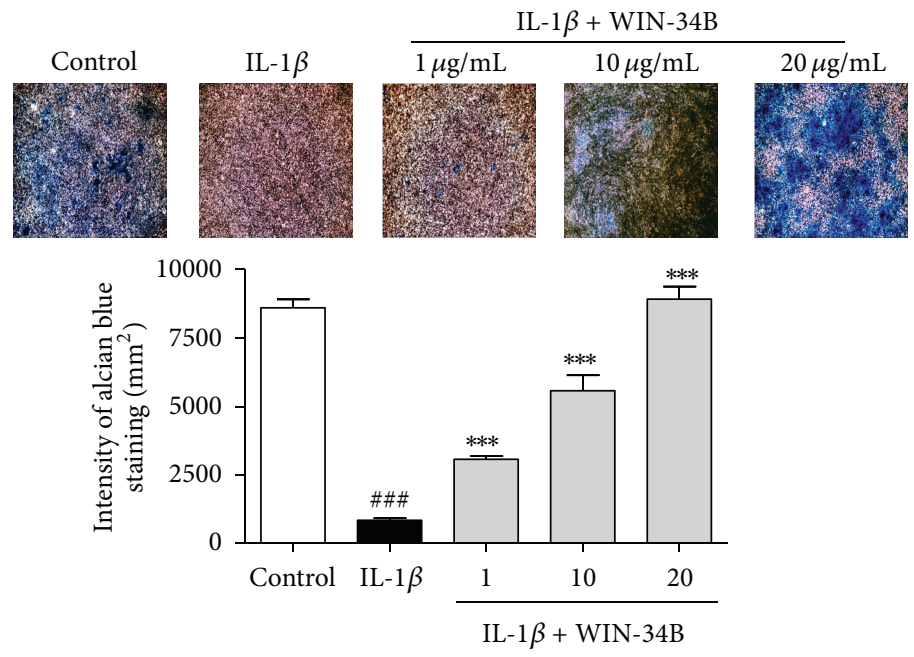

(a)

Chondrogenic marker genes

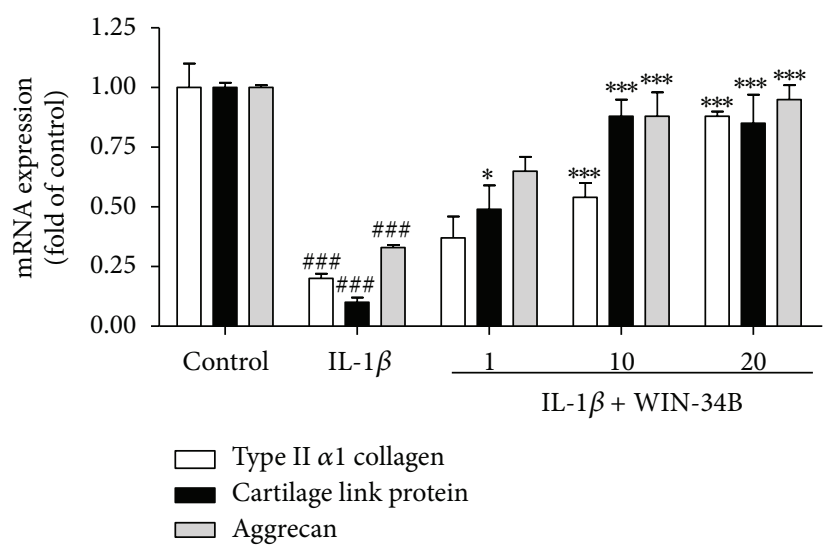

(b)
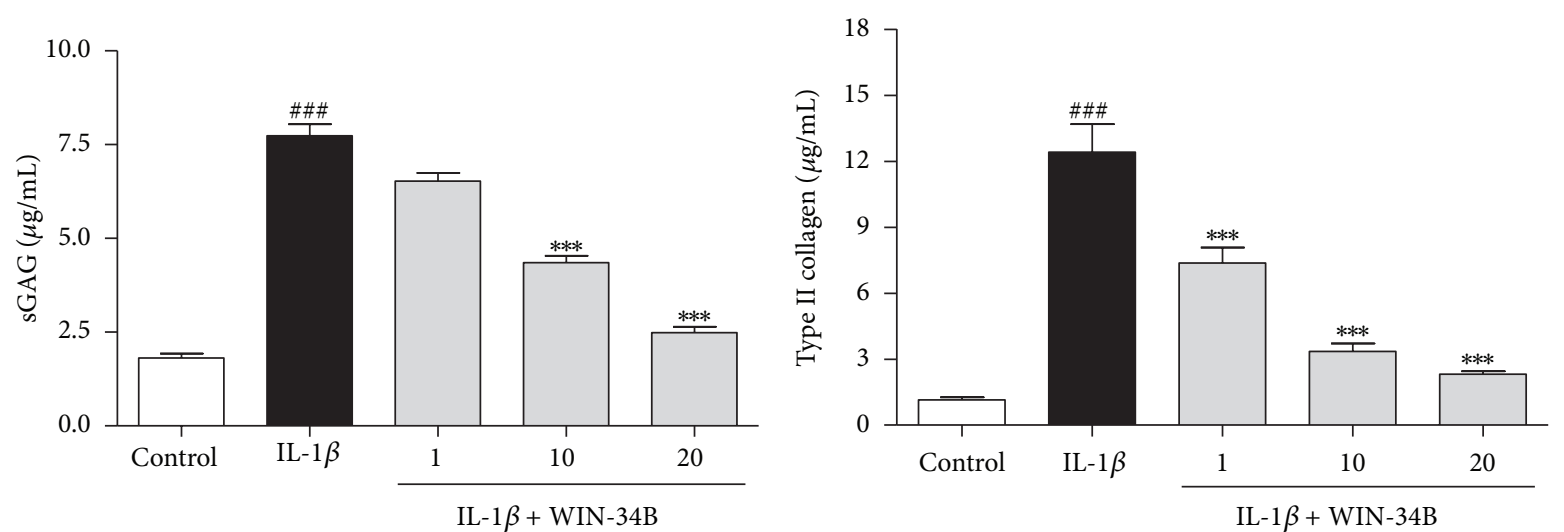

(c)

FIGURE 5: Effects of WIN-34B on chondrogenic differentiation of IL- $1 \beta$-stimulated progenitor cells from rabbit subchondral bone. (a) Histological analysis of WIN-34B by alcian blue staining of chondrogenic differentiation in IL-1 $\beta$-treated progenitor cells. Control, IL-1 $\beta$, WIN-34B $1 \mu \mathrm{g} / \mathrm{mL}, \mathrm{WIN}-34 \mathrm{~B} 10 \mu \mathrm{g} / \mathrm{mL}$, and WIN-34B $20 \mu \mathrm{g} / \mathrm{mL}$ after 7 days of culture in chondrogenic differentiation media. Magnified view $(\times 100)$. (b) Dose response of WIN-34B on the mRNA expression of chondrogenic markers. Chondrogenic differentiation of subchondral progenitor cells that were incubated for seven days with 1,10 , and $20 \mu \mathrm{g} / \mathrm{mL}$ of WIN-34B in the presence of IL- $1 \beta$. qRT-PCR was then performed for type II $\alpha 1$ collagen, cartilage link protein, and aggrecan. (c) Inhibitory effects of WIN-34B on GAG and type II collagen degradation on chondrogenic differentiation of IL- $1 \beta$-stimulated subchondral progenitor cells. GAG and type II collagen degradation are shown as a cumulative release into the culture medium. Values are the mean \pm SEM. ${ }^{\# \# \#} P<0.001$ compared to the control group. ${ }^{*} P<0.05$, ${ }^{* * *} P<0.001$ compared to the IL- $1 \beta$ group. Data were obtained from at least three independent experiments. 
the surgical and drug treatment of OA [38, 39]. Studies have attempted to find an effective combination of antigens in order to isolate a pure population of mesenchymal progenitor cells from various tissues [40]. One of these studies found that the coexpression of CD105 and CD73 could be sufficient in the adult human bone marrow cells [41]. Recently, micromass culture has been widely used to evaluate the chondrogenic potential of mesenchymal progenitor cells. Mesenchymal progenitor cells from human bone marrow increased the expression of type II and type X collagen in micromass culture [42]. Several studies reported that progenitor cells of human subchondral bone promoted the chondrogenic maker genes such as type II collagen, aggrecan, cartilage link protein, and cartilage oligomeric matrix protein [43-45]. In our study, WIN-34B increased the significant expression of CD105 and CD73 in the subchondral bone of collagenaseinduced osteoarthritis rabbit model. Moreover, type II collagen and aggrecan fully recovered from damage by WIN-34B at $200 \mathrm{mg} / \mathrm{kg}$. WIN-34B at $10 \mu \mathrm{g} / \mathrm{mL}$ increased the number of $\mathrm{SH}-2$ cells and expression of type II collagen in subchondral progenitor cells. Furthermore, WIN-34B strongly induced proteoglycan, type II $\alpha 1$ collagen, cartilage link protein, and aggrecan and reduced the degradation of GAG and type II collagen in the IL- $1 \beta$-treated subchondral progenitor cells. Therefore, we suggest that WIN-34B strongly induced chondrogenic differentiation by the induction of typical mesenchymal stem cell related cell surface antigen CD105 and $\mathrm{CD} 73$, and the enhancement of chondrogenic markers type II collagen and aggrecan in vivo and in vitro.

In summary, it was shown that WIN-34B exerted cartilage protection and chondrogenic differentiation in the collagenase-induced osteoarthritis rabbit model and progenitor cells from subchondral bone by stimulating chondrogenic differentiation of progenitor cells derived from subchondral bone. These results suggest that WIN-34B has potential for a new disease-modifying osteoarthritis drug (DMOAD) candidate in OA treatment.

\section{Conflict of Interests}

The authors have declared that there is no conflict of interests.

\section{Authors' Contribution}

Jeong-Eun Huh and Yeon-Cheol Park contributed equally to this work.

\section{Acknowledgment}

This work was supported by the Basic Science Research Program through the National Research Foundation of Korea (NRF), funded by the Ministry of Education, Science and Technology (2011-0012672 and 2011-0006033).

\section{References}

[1] A. R. Poole, "An introduction to the pathophysiology of osteoarthritis," Frontiers in Bioscience, vol. 4, pp. D662-D670, 1999.
[2] L. G. Ameye and W. S. S. Chee, "Osteoarthritis and nutrition. From nutraceuticals to functional foods: a systematic review of the scientific evidence," Arthritis Research and Therapy, vol. 8, no. 4, article R127, 2006.

[3] J. Martel-Pelletier, C. Boileau, J. Pelletier, and P. J. Roughley, "Cartilage in normal and osteoarthritis conditions," Best Practice and Research: Clinical Rheumatology, vol. 22, no. 2, pp. 351384, 2008.

[4] A. M. Coats, P. Zioupos, and R. M. Aspden, "Material properties of subchondral bone from patients with osteoporosis or osteoarthritis by microindentation testing and electron probe microanalysis," Calcified Tissue International, vol. 73, no. 1, pp. 66-71, 2003.

[5] D. B. Burr, "Increased biological activity of subchondral mineralized tissues underlies the progressive deterioration of articular cartilage in osteoarthrosis," Journal of Rheumatology, vol. 32, no. 6, pp. 1156-1158, 2005.

[6] A. P. Newman, "Articular cartilage repair," The American Journal of Sports Medicine, vol. 26, no. 2, pp. 309-324, 1998.

[7] F. Shapiro, S. Koide, and M. J. Glimcher, "Cell origin and differentiation in the repair of full-thickness defects of articular cartilage," Journal of Bone and Joint Surgery A, vol. 75, no. 4, pp. 532-553, 1993.

[8] D. B. Burr and M. A. Gallant, "Bone remodelling in osteoarthritis," Nature Review Rheumatology, vol. 8, no. 11, pp. 665-673, 2012.

[9] E. L. Radin and R. M. Rose, "Role of subchondral bone in the initiation and progression of cartilage damage," Clinical Orthopaedics and Related Research, vol. 213, pp. 34-40, 1986.

[10] M. Merashly and I. Uthman, "Management of knee osteoarthritis: an evidence based review of treatment options," The Lebanese Medical Journal, vol. 60, no. 4, pp. 237-242, 2012.

[11] S. Castañeda, J. A. Roman-Blas, R. Largo, and G. HerreroBeaumont, "Subchondral bone as a key target for osteoarthritis treatment," Biochemical Pharmacology, vol. 83, no. 3, pp. 315323, 2012.

[12] F. Berenbaum, "Osteoarthritis year 2010 in review: pharmacological therapies," Osteoarthritis and Cartilage, vol. 19, no. 4, pp. 361-365, 2011.

[13] M. Kang, I. Jung, J. Hur et al., "The analgesic and antiinflammatory effect of WIN-34B, a new herbal formula for osteoarthritis composed of Lonicera japonica Thunb and Anemarrhena asphodeloides BUNGE in vivo," Journal of Ethnopharmacology, vol. 131, no. 2, pp. 485-496, 2010.

[14] J. E. Huh, W. I. Lee, B. K. Seo et al., "Gastroprotective and safety effects of WIN-34B, a novel treatment for osteoarthritis, compared to NSAIDs," Journal of Ethnopharmacology, vol. 137, no. 2, pp. 1011-1017, 2011.

[15] J. E. Huh, B. K. Seo, Y. C. Park et al., "WIN-34B, a new herbal medicine, inhibits the inflammatory response by inactivating $\mathrm{I} \kappa \mathrm{B}-\alpha$ phosphorylation and mitogen activated protein kinase pathways in fibroblast-like synoviocytes," Journal of Ethnopharmacology, vol. 143, no. 3, pp. 779-786, 2012.

[16] J. E. Huh, B. K. Seo, Y. H. Baek et al., "Standardized butanol fraction of WIN-34B suppresses cartilage destruction via inhibited production of matrix metalloproteinase and inflammatory mediator in osteoarthritis human cartilage explants culture and chondrocytes," BMC Complementary and Alternative Medicine, vol. 12, article 256, 2012.

[17] T. Kikuchi, T. Sakuta, and T. Yamaguchi, "Intra-articular injection of collagenase induces experimental osteoarthritis in 
mature rabbits," Osteoarthritis and Cartilage, vol. 6, no. 3, pp. 177-186, 1998.

[18] C. Colombo, M. Butler, E. O’Byrne et al., "A new model of osteoarthritis in rabbits. I. Development of knee joint pathology following lateral meniscectomy and section of the fibular collateral and sesamoid ligaments," Arthritis and Rheumatism, vol. 26, no. 7, pp. 875-886, 1983.

[19] T. Kikuchi, H. Yamada, and M. Shimmei, "Effect of high molecular weight hyaluronan on cartilage degeneration in a rabbit model of osteoarthritis," Osteoarthritis and Cartilage, vol. 4, no. 2, pp. 99-110, 1996.

[20] P. Pastoureau, S. Leduc, A. Chomel, and F. de Ceuninck, "Quantitative assessment of articular cartilage and subchondral bone histology in the meniscectomized guinea pig model of osteoarthritis," Osteoarthritis and Cartilage, vol. 11, no. 6, pp. 412-423, 2003.

[21] M. Sabatini, C. Lesur, M. Thomas et al., "Effect of inhibition of matrix metalloproteinases on cartilage loss in vitro and in a guinea pig model of osteoarthritis," Arthritis and Rheumatism, vol. 52, no. 1, pp. 171-180, 2005.

[22] B. Johnstone, T. M. Hering, A. I. Caplan, V. M. Goldberg, and J. U. Yoo, "In vitro chondrogenesis of bone marrow-derived mesenchymal progenitor cells," Experimental Cell Research, vol. 238, no. 1, pp. 265-272, 1998.

[23] J. R. Steadman, K. K. Briggs, J. J. Rodrigo, M. S. Kocher, T. J. Gill, and W. G. Rodkey, "Outcomes of microfracture for traumatic chondral defects of the knee: average 11-year follow-up," Arthroscopy, vol. 19, no. 5, pp. 477-484, 2003.

[24] L. Hangody, P. Feczkó, L. Bartha, G. Bodó, and G. Kish, "Mosaicplasty for the treatment of articular defects of the knee and ankle," Clinical Orthopaedics and Related Research, no. 391, pp. S328-S336, 2001.

[25] J. D. Harris, R. A. Siston, X. Pan, and D. C. Flanigan, "Autologous chondrocyte implantation: a systematic review," Journal of Bone and Joint Surgery A, vol. 92, no. 12, pp. 2220-2233, 2010.

[26] H. Koga, L. Engebretsen, J. E. Brinchmann, T. Muneta, and I. Sekiya, "Mesenchymal stem cell-based therapy for cartilage repair: a review," Knee Surgery, Sports Traumatology, Arthroscopy, vol. 17, no. 11, pp. 1289-1297, 2009.

[27] K. D. Ham, R. F. Loeser, B. R. Lindgren, and C. S. Carlson, "Effects of long-term estrogen replacement therapy on osteoarthritis severity in cynomolgus monkeys," Arthritis and Rheumatism, vol. 46, no. 7, pp. 1956-1964, 2002.

[28] T. Y. Ho, K. Santora, J. C. Chen, A. L. Frankshun, and C. A. Bagnell, "Effects of relaxin and estrogens on bone remodeling markers, receptor activator of NF-kB ligand (RANKL) and osteoprotegerin (OPG), in rat adjuvant-induced arthritis," Bone, vol. 48, no. 6, pp. 1346-1353, 2011.

[29] M. Z. Yan, Y. Xu, Y. X. Gong et al., "Raloxifene inhibits bone loss and improves bone strength through an Opg-independent mechanism," Endocrine, vol. 37, no. 1, pp. 55-61, 2010.

[30] S. Canpolat, N. Tug, A. D. Seyran, S. Kumru, and B. Yilmaz, "Effects of raloxifene and estradiol on bone turnover parameters in intact and ovariectomized rats," Journal of Physiology and Biochemistry, vol. 66, no. 1, pp. 23-28, 2010.

[31] M. A. Karsdal, I. Byrjalsen, D. J. Leeming, and C. Christiansen, "Tibolone inhibits bone resorption without secondary positive effects on cartilage degradation," BMC Musculoskeletal Disorders, vol. 9, article 153, 2008.

[32] A. Kadri, T. Funck-Brentano, H. Lin et al., "Inhibition of bone resorption blunts osteoarthritis in mice with high bone remodelling," Annals of the Rheumatic Diseases, vol. 69, no. 8, pp. 1533-1538, 2010.

[33] M. Moreau, P. Rialland, J. Pelletier et al., "Tiludronate treatment improves structural changes and symptoms of osteoarthritis in the canine anterior cruciate ligament model," Arthritis Research and Therapy, vol. 13, no. 3, article R98, 2011.

[34] G. Herrero-Beaumont, J. A. Roman-Blas, S. Castañeda, and S. A. Jimenez, "Primary osteoarthritis no longer primary: three subsets with distinct etiological, clinical, and therapeutic characteristics," Seminars in Arthritis and Rheumatism, vol. 39, no. 2, pp. 71-80, 2009.

[35] J. K. Chang, L. H. Chang, S. H. Hung et al., "Parathyroid hormone 1-34 inhibits terminal differentiation of human articular chondrocytes and osteoarthritis progression in rats," Arthritis and Rheumatism, vol. 60, no. 10, pp. 3049-3060, 2009.

[36] O. Malaise, O. Bruyere, and J. Y. Reginster, "Strontium ranelate normalizes bone mineral density in osteopenic patients," Aging-Clinical and Experimental Research, vol. 19, no. 4, pp. 330-333, 2007.

[37] D. T. Felson, R. C. Lawrence, M. C. Hochberg et al., "Osteoarthritis: new insights-part 2: treatment approaches," Annals of Internal Medicine, vol. 133, no. 9, pp. 726-737, 2000.

[38] H. J. Mankin, “The response of articular cartilage to mechanical injury," Journal of Bone and Joint Surgery A, vol. 64, no. 3, pp. 460-466, 1982.

[39] W. S. Khan, D. S. Johnson, and T. E. Hardingham, “The potential of stem cells in the treatment of knee cartilage defects," Knee, vol. 17, no. 6, pp. 369-374, 2010.

[40] S. Bobis, D. Jarocha, and M. Majka, "Mesenchymal stem cells: characteristics and clinical applications," Folia Histochemica et Cytobiologica, vol. 44, no. 4, pp. 215-230, 2006.

[41] M. F. Pittenger, A. M. Mackay, S. C. Beck et al., "Multilineage potential of adult human mesenchymal stem cells," Science, vol. 284, no. 5411, pp. 143-147, 1999.

[42] S. Ichinose, K. Yamagata, I. Sekiya, T. Muneta, and M. Tagami, "Detailed examination of cartilage formation and endochondral ossification using human mesenchymal stem cells," Clinical and Experimental Pharmacology and Physiology, vol. 32, no. 7, pp. 561-570, 2005.

[43] J. E. Huh, Y. J. Ch, M. C. Yoo et al., "Induction of effective osteogenesis by mesenchymal stem cells from the human subchondral bone," Journal of Korean Acupuncture and Moixibution Society, vol. 23, no. 5, pp. 69-77, 2006.

[44] M. Endres, K. Neumann, T. Häupl et al., "Synovial fluid recruits human mesenchymal progenitors from subchondral spongious bone marrow," Journal of Orthopaedic Research, vol. 25, no. 10, pp. 1299-1307, 2007.

[45] K. Neumann, T. Dehne, M. Endres et al., "Chondrogenic differentiation capacity of human mesenchymal progenitor cells derived from subchondral cortico-spongious bone," Journal of Orthopaedic Research, vol. 26, no. 11, pp. 1449-1456, 2008. 


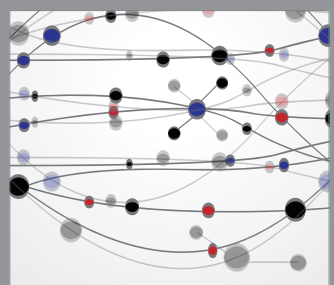

The Scientific World Journal
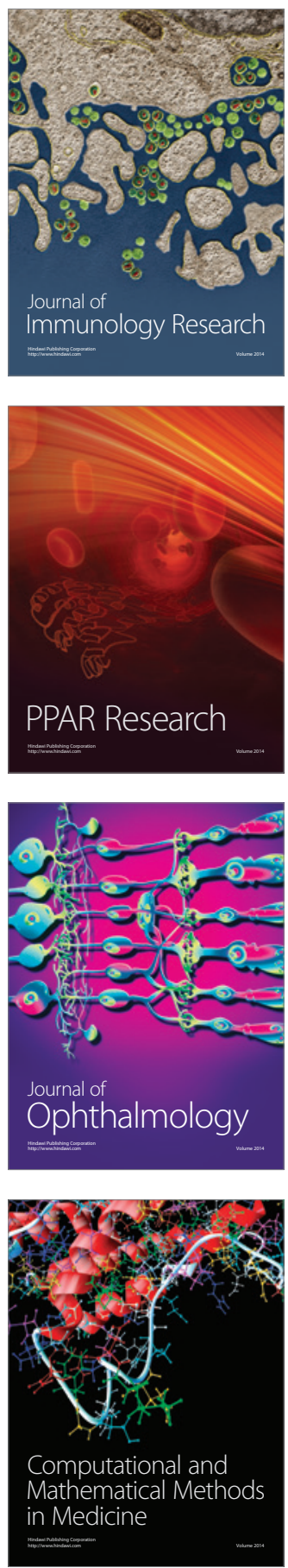

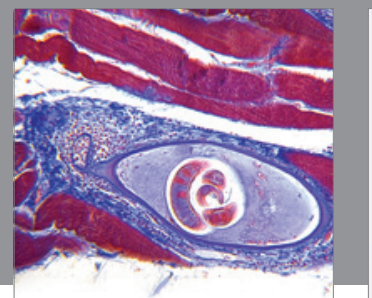

Gastroenterology

Research and Practice
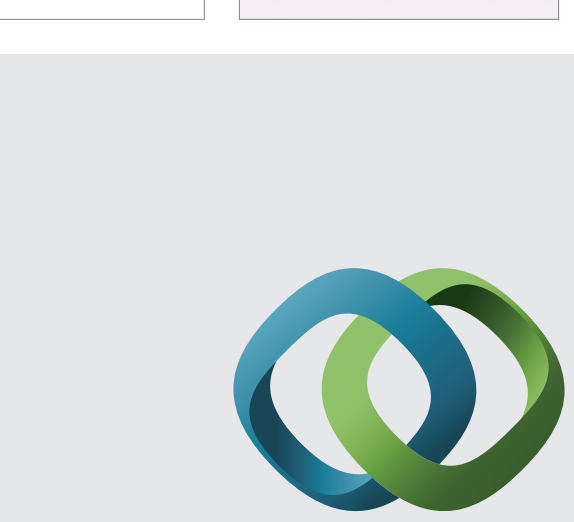

\section{Hindawi}

Submit your manuscripts at

http://www.hindawi.com

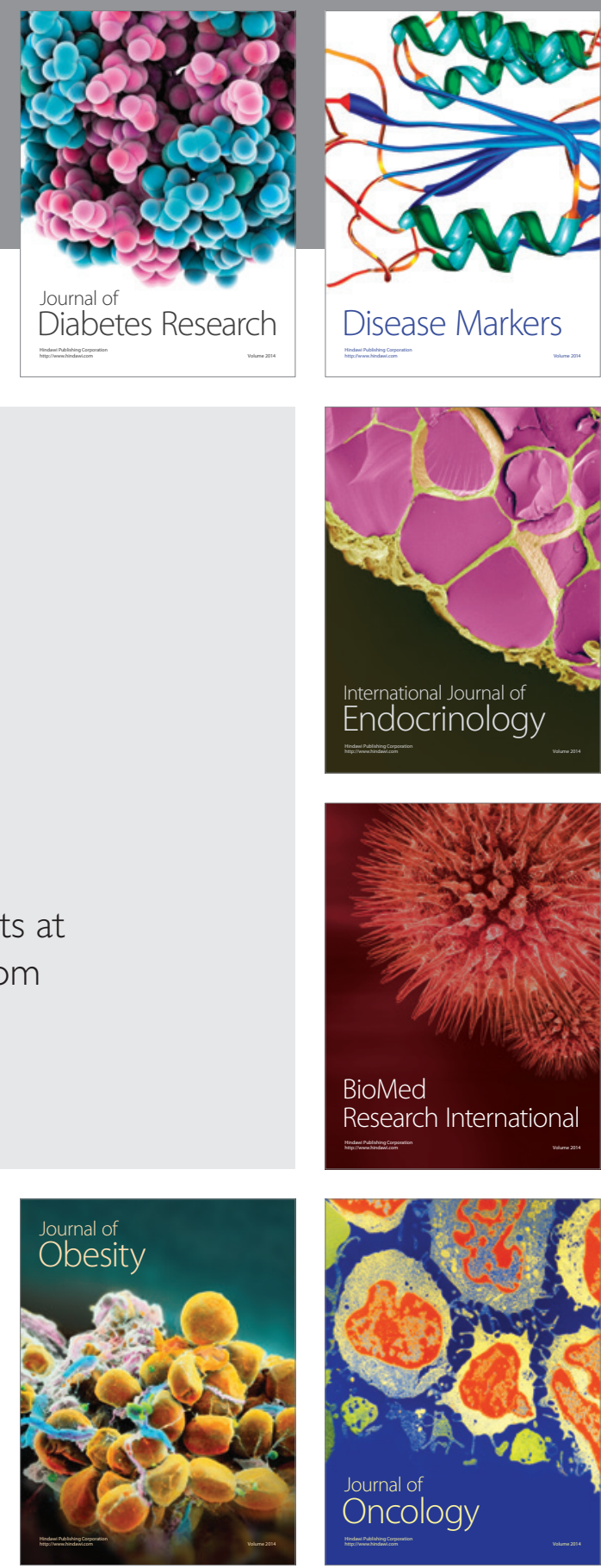

Disease Markers
